\title{
Clinical and microbiological characteristics of Cryptococcus gattii isolated from 7 hospitals in China
}

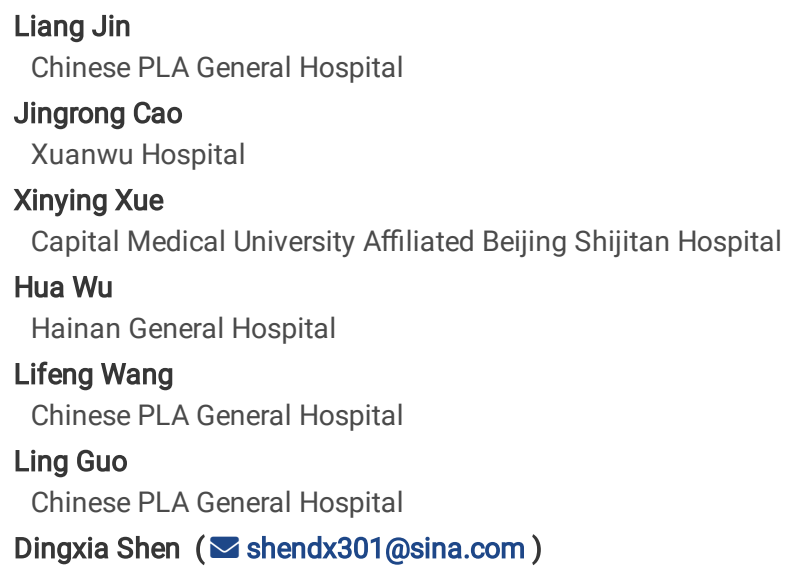

Version of Record: A version of this preprint was published at BMC Microbiology on March 30th, 2020. See the published version at https://doi.org/10.1186/s12866-020-01752-4. 


\section{Abstract}

Background: Infection, even outbreak, caused by Cryptococcus gattii (C. gattii ) has been reported in Canada and the United States, but there were sparsely-reported cases of C. gattii in China. Our interest in occurrence, clinical manifestation, laboratory identification and molecular characterization of Chinese C. gattii strains leads us to this research. Results: Out of 254 clinical isolates, initially identified as Cryptococcus neoformans (C. neoformans ), eight strains were re-identified as C. gattii. Multi-locus sequence typing (MLST) showed genotype VGI accounted for the most (6 / 8), the other two strains were genotype VGII『VGIla and VGIIb respectively \with 3 specific spectra of molecular weight about 4342, 8686, 9611 Dalton by MALDI-TOF MS. The minimal inhibitory concentrations (MICs) of Fluconazole with Yeast one was $2 \varangle 4$ times higher than that with ATB fungus 3 and MICs of antifungal agents against VGII strains were higher than against VGI strains. Comparative proteome analysis showed that 329 and 180 proteins were highly expressed by C. gattii VGI and VGII respectively. The enrichment of differentially expressed proteins was directed to Golgi complex.Conclusions: Infection by C. gattii in China occurred sparsely. Genotype VGI was predominant but VGII was more resistant to antifungal agents. There was significant difference in protein expression profile between isolates of VGI and VGII C. gattii. Key words: Cryptococcus gattii, Genotype, Antifungal agents, Spectrum, differential protein

\section{Background}

Cryptococcus gattii (C. gattii), one of the most common pathogenic cryptococcal species, primarily infects immunocompetent hosts, in contrast to Cryptococcus neoformans (C. neoformans), which mainly infects immunocompromised individuals [1, 2]凶Previous studies revealed that $C$. gattii infection was restricted geographically to tropical and subtropical regions [1-3]. However, outbreaks have been recorded in temperate regions, such as British Columbian of Canada and Pacific Northwest of the United States $[4,5]$. The majority of Chinese people reside in temperate and subtropical regions with climates suitable for fungal growth and the incidence of cryptococcal infection increased in recent years, unfortunately, little investigation has been carried out on this organism in China [6]. The objectives of the present study were to determine the frequency of $C$. gattii infection, to investigate clinical and microbiological characterization, and to analyze molecular features of the Chinese isolates

\section{Results}

1. Identification and antifungal susceptibility profile of gattii isolates

Among 254 collected Cryptococcal strains, eight showed blue pigmentation on canavanine glycine bromothymol blue (CGB) agar and were characterized as . gattii by matrix-assisted laser desorption/ionization time-of-flight mass spectrometry (MALDI-TOF MS ) with scores from 2.043 to 2.275 , otherwise they were all identified as $C$.neoformans by VITEK 2 compact as seen in Table 1. The mass spectra obtained from eight $C$. gattii isolates were characterized by diverse spectra in the range between 2000 and 10000 Dalton. Three specific spectra with molecular weight of about $4342,8686,9611$ Dalton could be seen in two isolates of $C$. gattii VGII, they were absent in six isolates of $C$. gattii VGI, as shown in Fig.1. The dendrogram created by MALDI Biotyper divided eight isolates into two groups of $C$. gattii VGI and VGIl as shown in Fig.2. The MICs of six antifungal drugs to eight strains of $C$. gattii were listed in Table 1.

\section{MLST analysis and Genotyping}

MLST confirmed six strains of $C$. gattii VGI and two strains of $C$. gattii VGII as indicated in supplementary Table 1 . The 2 strains of isolate number 1 and 6 with C.gattii genotype VGII could be subtyped into VGIla and VGIlb respectively by further comparison with Vancouver Island reference stains of R265 and R272, as in supplementary Table 2. Some gene mutation existed in unlinked gene loci such as FTR1 and RAS1 as indicated in Fig.3.

\section{Clinical information of patients infected with $C$. gattii}

As shown in Table 1, the eight strains of $C$. gattii were isolated from eight patients. Two patients with isolate numbers of 2 and 6 were from Hainan and Yunnan Province, which were recognized as tropical areas. Three patients with isolate number 3 (from Chongqing city), 4 and 7 (from Fujian Province) were recognized as being from subtropical area. The other three patients with isolate numbers of 1, 5 and 8 were from Shandong Province, Inner Mongolia Autonomous Region and Henan Province, which were recognized as temperate regions. Information of patient infected with isolate number 3 was unavailable, the other 7 patients were immunocompetent young male adults, with age range of $21 \bowtie 60$ years old. Their clinical and laboratory information were summarized in Table 2.

\section{Differential protein analysis between gattii VGI and VGII}

In this study, the proteome expression profiles of two strains of VGII and four strains of VGI C. gattii were created. A total of 3628 proteins were identified, of which, 2436 proteins were found in both VGII and VGI C. gattii, however, C. gattii genotype VGI and VGII possessed 774 and 418 specific proteins respectively. Comparative proteome analysis showed that 329 and 180 proteins were highly expressed in C. gattii VGI and VGII as shown in Fig.4. A cluster analysis of the differentially expressed proteins was shown in Fig. 5.

The information of GO term and KEGG metabolic pathway analysis indicated that the enrichment of differential expressed proteins between VGI and VGII was mainly directed to Golgi apparatus, Golgi membrane and Golgi vesicle as shown in Table 3. The most significant enriched metabolic pathways were oxidative phosphorylation, ribosome and metabolic pathway as shown in Fig.6.

\section{Discussion}


1. Selection of identification method and drug resistance of Chinese $C$. gattii strains

C. neoformans and $C$. gattii are two important fungal pathogens for humans and animals. Both of them are round with capsule and positive urease test. These routine laboratory identification methods are unable to distinguish the two species [7]. Although there were several reports about infection of $C$. gattii from China [8-10], the number of $C$. gattii infections may have been underestimated because most laboratories utilize ink staining and biochemical methods, like VITEK 2 compact, for routine identificatio. CGB agar was recommended to identify $C$. gattii from $C$. neoformans due to its convenience and low cost [7], but it took longer time to get the result. Molecular methods would be faster and more accurate for differentiation of the two pathogenic Cryptococci species. However, they are not available in all clinical laboratories, where an accurate identificaction of species should be made in order to install the proper treatment. In this study, eight strains of $C$. gattii were not only correctly identified but also grouped by MALDI-TOF MS with Bruker software 3.0. Of course, eight strains was not enough and more strains should be studied to obtain the spectrum difference between groups of $C$. gattii.

The results of antifungal susceptibility test by two kits were in good agreement, except that MICs of Fluconazole were $2 \varangle 4$ times higher by Yeast one than by ATB fungus 3. All the C.gattii isolates were susceptible to 5-Flucytosine, Amphotericin B, Itraconazole, Voriconazole and Posaconazole, only one strain was resistant to Fluconazole with MIC of 128 by Yeast one. However, interpretation of MICs of antifungal agents including Fluconazole for category of "susceptibility" or "resistance" was hampered by the lack of clinical breakpoints for $C$. gattii. Some previous studies have shown that $C$. gattii may be less susceptible to antifungal agents compared with $C$. neoformans. In a study from Taiwan, $C$. gattii was less susceptible to 5 -Flucytosine and amphotericin B, and in Spain, MICs of Fluconazole, Voriconazole and Posaconazole to $C$. gattii were significantly higher [11-13]. The correlation between susceptibility profile and genotype of $C$. gattii has rarely been studied [14], our data indicated that antifungal agents exhibited higher MICs against isolates of genotype VGII than genotype VGI, which agreed with the data of Hagen et al and Lockhart et al. [14-17]. However, Clinical relevance between MIC breakpoint and epidemiological cut-off value (ECV) based on MIC distributions of wild-type strains has currently been studied on both $C$. neoformans and $C$. gattii isolates

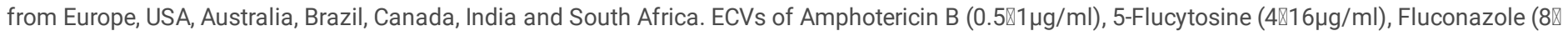
$32 \mu \mathrm{g} / \mathrm{ml}$ ) and other azoles varied similarly by molecular type for both C. neoformans and C. gattĩ $[15,16]$.

\section{Molecular and epidemical characteristics of Chinese C. gattii strains}

Up to now, four genotypes of $C$. gattii have been detected, they were VGI, VGII, VGIII and VGIV. Lockhart and colleagues had reported that VGII and VGIII were the most-frequently identified isolates in America, VGIV was almost exclusively in Africa, and VGI predominated in Europe, Australia and Asia [18]. C. gattii, as an important pathogen, caused outbreak in British Columbia, Canada and the Pacific Northwest, the United States. But 8 strains in our study were pathogens causing sporadic infections according to the strain origination and their isolation time.

\section{Patient information and clinical characteristics}

All the patients in our study had no recent travel history, the $C$. gattii infection occurred regionally and domestically. They were immunocompetent young male adults with age range of $21 \otimes 60$ years old, which was considered as the reason for increased exposure to environmental sources and increased

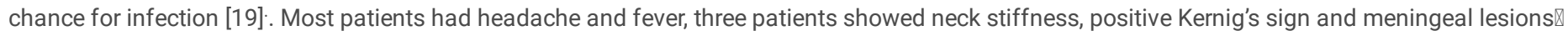
meningeal enhancement or lacunar infarction by brain MRI. Most of them also demonstrated irregular nodule, consolidation and mass by lung CT, which was consistent with the research made by Ngamskulrungroj who indicated that $C$. gattii could cause fatal lung infection [20].

It was reported that host response varied based on the genotype of the organism and concomitant illnesses [21]. There was also study which revealed that C. gattii VGII strains were more virulent than VGI strains and VGIla were even more virulent than VGIlb independent of their clinical or environmental origin [22]. In our study, all patients were treated by Fluconazole plus amphotericin B, most of them improved effectively without severe neurological sequelae. This might be explained by the fact that these patients infected by $C$. gattii VGI more than $C$. gattii VGII on the one hand, and on the other hand, two of them were infected with $C$. gattii VGII which showed sequence mutations in the gene location of RAS1 and FTR1 compared with reference strains of R265 and R272 respectively. Whether the mutations were relevant to virulence decrease, further work needs to be done.

\section{Analysis of differentially expressed protein in two genotypes of C. gattii.}

Our study showed significant difference in protein expression spectra between VGI and VGII. GO is a very important tool of biological information. By establishing a set of controlled words with dynamic form, the attributes of genes and gene products in organisms can be described comprehensively. KEGG is the main public database with which the most important biochemical metabolic pathways and signal transduction pathways can be determined. Our results suggested that the differential protein of $C$. gattii VGI and VG II was mainly located on the organelles associated with the Golgi body, which meant energy metabolism of $C$. gattii might be involved in the difference of pathogenesis mechanism for different genotype of $C$. gattii. Study on the secretory protein and the secretory vesicles of the two genotypes of $C$. gattii would be beneficial to the understanding of the pathogenesis of $C$. gattii.

\section{Conclusions}

In spite that only 8 strains were available for analysis, our results demonstrated that $C$. gattii genotype VGI was predominant in China and $C$. gattii genotype VGII was more resistant to antifungal agents. C. gattii VGII isolates possessed obvious protein peaks with molecular weight of approximate 4342 , 8686, 9611 Dalton. The full protein spectrum data of C.gattii were provided for the first time, a total of 3628 proteins were identified, 329 and 180 proteins were highly expressed by $C$. gattii VGI and VGII respectively. The enrichment of differentially expressed proteins between VGI and VGII was mainly directed to Golgi complex. It will lay a foundation for better understanding and further research on the pathogenic mechanism for different genotype of $C$. gattii. 


\section{Methods}

1. Collection and initial identification of clinical isolates

A total of 254 clinical isolates initially identified as $C$. neoformans by biochemical methods were collected from seven hospitals in China, they were all stored at $-80^{\circ} \mathrm{C}$. All the isolates were sub-cultured onto Sabouraud dextrose agar medium at $25^{\circ} \mathrm{C}$ for $48 \otimes 72 \mathrm{~h}$ and identified by VITEK $2 \mathrm{Compact}$ (bioMérieux SA, France). Each isolate was also inoculated on canavanine-glycine-bromthymol blue (CGB) agar [23] at $25^{\circ} \mathrm{C}$ for $24 \rrbracket 120 \mathrm{~h}, \mathrm{The}$ isolates which showed blue pigmentation on CGB agar were then subjected to further identification.

\section{Identification by MALDI-TOF MS}

Isolates were re-identified and analyzed by MALDI-TOF MS (Bruker, Daltonik, Bremen, Germany). Briefly, one single colony was smeared directly on the MALDI-TOF MS analysis plate and formic acid was added. After $3 \varangle 5$ minutes, matrix was added and the plate was put into the MALDI-TOF MS instrument with MALDI Biotyper software 3.0 (Bruker Daltonik $\mathrm{GmbH}$ ) for species identification and dendrogram analysis. Two strains of $C$.neoformans were included as outgroup control.

\section{Analysis by multilocus sequence typing (MLST)}

Genomic DNA of each isolate identified as $C$. gattii was then extracted using the TianGen® TIANamp Yeast DNA Kit (Tiangen Biotech Beijing CO., LTD, China) complying with the manufacturer's instruction, seven genes of unlinked loci were amplified, including six housekeeping genes (CAP59, GPD1, LAC1, PLB1, SOD1, URA5) and one non-coding region gene (IGS1)[24] , bi-directional sequencing for each gene was then carried out, sequence comparison for each locus was done according to the method described by ISHAM Cryptococcal Working Group. Sequences were uploaded to the MLST Database for the C.neoformans/C.gattii species complex (http://mlst.mycologylab.org) one by one. A sequence type (ST) number and seven allele type (AT) numbers were given to each isolate. New AT and ST number will be assigned for new sequence. To differentiate VGIl subtypes, twelve unlinked genes (SXI1a, TEF1, FTR1, CBP1, ICL1, HOG1, TOR1, STE7, TRR1, FHB1, RAS1, PAK1) were also amplified and sequenced according to the method of Fraser et al [25], they were analyzed and compared with Vancouver Island strains of R265 and R272.

4. Antifungal susceptibility test of $C$. gattii isolates

Antifungal susceptibility test was carried out by both ATB fungus 3 (bioMérieux SA, France) and Yeast one (Trek Diagnostic Systems Ltd, UK) following their instructions. Candida krusei ATCC 6258 and Candida parapsilosis ATCC 22019 were used for quality control.

5. Clinical information of patients

Under authorization of Medical Record Department, Clinical information of patients infected by C. gattii was reviewed retrospectively, including age, sex, underlying diseases, symptoms, imaging findings, laboratory examinations and antifungal therapy.

6. Analysis of differential proteins

According to the regional distribution and the integrity of clinical data of the strains, six strains (4 of VGI and 2 of VGII) of $C$. gattii were selected for proteome analysis. All the isolates were sub-cultured onto Sabouraud dextrose agar medium, incubated at $25^{\circ} \mathrm{C}$ for $48 \otimes 72 \mathrm{~h} \otimes$ the proteins were extracted from the strains, The protein concentration was $0.5 \mu \mathrm{g} / \mu \mathrm{l}$, after being separated by SDS-PAGE electrophoresis (One-dimensional), the proteins were hydrolyzed and analyzed. Original mass spectrum files of 6 strains were imported into Maxquatt software (version 1.3.0.5) for analysis. The database source was for C.gattii. in Uniprot囚http://www.geneontology.org/ . Plus or minus 15ppm of polypeptide molecular weight, or missing 2 cutting sites were set as Maxquatt parameters, false discovery rate (FDR) for polypeptide identification was set as 0.01 . A standard of $p<0.05$ and 2 -fold expression were considered as different proteins. The enrichment and pathway analysis was carried out by using the GO plot package of R language and KEGG online tool (https://david.ncifcrf.gov/, http://www.kegg.jp/kegg/pathway.html). The bubble diagram was drawn according to the R language ggplot2 package.

\section{Abbreviations}

$\begin{array}{ll}\text { AMB } & \text { Amphotericin B } \\ \text { AT } & \text { Allele type } \\ \text { CGB } & \text { Canavanine glycine bromothymol blue } \\ \text { C.gattii } & \text { Cryptococcus gattii } \\ \text { C.neoformans Cryptococcus neoformans } \\ \text { ECVs } \quad \text { Epidemiological MIC cut-off values } \\ \text { FCA } \quad \text { Fluconazole } \\ \text { FDR } & \text { False discovery rate }\end{array}$


MALDI-TOF MS Matrix-assisted laser desorption/ionization time-of-flight mass spectrometry

$\begin{array}{ll}\text { MICs } & \text { Minimal inhibitory concentrations } \\ \text { MLST } & \text { Multi-locus sequence typing } \\ \text { PSZ } & \text { Posaconazole } \\ \text { ST } & \text { Sequence type } \\ \text { VRC } & \text { Voriconazole } \\ \text { 5-FU } & \text { 5-Flucytosine }\end{array}$

\section{Declarations}

\section{Ethics approval and consent to participate: Not applicable}

Consent for publication: Not applicable.

Availability of data and materials: The datasets used and/or analyzed during the current study are available from the corresponding author and first author on reasonable request.

Competing interests: The authors declare that there are no competing interests.

Funding: This work was supported by Translational Medicine Project of Chinese General Hospital (grant no.2018TM-12). The funds are mainly used for the purchase of reagents, gene sequencing and proteomics analysis.

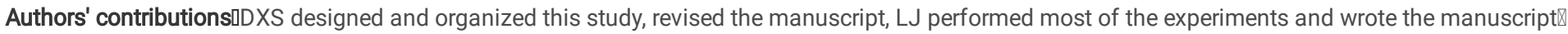
XYX collected strains, analyzed the sequence, HW, LFW and LG collected and identified strains, JRC performed and analyzed MALDI-TOF MS. All authors read and approved the final manuscript.

Acknowledgements: Not applicable

\section{References}

1. Kwon-Chung KJ, Bennett JE: Epidemiologic differences between the two varieties of Cryptococcus neoformans. Am J Epidemiol. 1984, 120(1):123130.

2. Chen S, Sorrell T, Nimmo G, Speed B, Currie B, Ellis D, Marriott D, Pfeiffer T, Parr D, Byth K: Epidemiology and host- and variety-dependent characteristics of infection due to Cryptococcus neoformans in Australia and New Zealand. Australasian Cryptococcal Study Group. Clin Infect Dis. 2000, 31(2):499-508.

3. Harris J, Lockhart S, Chiller T: Cryptococcus gattii: where do we go from here? Med Mycol. 2012, 50(2):113-129.

4. Kidd SE, Hagen F, Tscharke RL, Huynh M, Bartlett KH, Fyfe M, Macdougall L, Boekhout T, Kwon-Chung KJ, Meyer W: A rare genotype of Cryptococcus gattii caused the cryptococcosis outbreak on Vancouver Island (British Columbia, Canada). Proc Natl Acad Sci U S A. 2004, 101(49):17258-17263.

5. Byrnes EJ, 3rd, Li W, Lewit Y, Ma H, Voelz K, Ren P, Carter DA, Chaturvedi V, Bildfell RJ, May RC et al: Emergence and pathogenicity of highly virulent Cryptococcus gattii genotypes in the northwest United States. PLoS Pathog. 2010, 6(4):e1000850.

6. Fang W, Fa Z, Liao W: Epidemiology of Cryptococcus and cryptococcosis in China. Fungal Genet Biol. 2015, 78:7-15.

7. Klein KR, Hall L, Deml SM, Rysavy JM, Wohlfiel SL, Wengenack NL: Identification of Cryptococcus gattii by use of L-canavanine glycine bromothymol blue medium and DNA sequencing. J Clin Microbiol. 2009, 47(11):3669-3672.

8. Chen J, Varma A, Diaz MR, Litvintseva AP, Wollenberg KK, Kwon-Chung KJ: Cryptococcus neoformans strains and infection in apparently immunocompetent patients, China. Emerg Infect Dis. 2008, 14(5):755-762.

9. Feng X, Yao Z, Ren D, Liao W, Wu J: Genotype and mating type analysis of Cryptococcus neoformans and Cryptococcus gattii isolates from China that mainly originated from non-HIV-infected patients. FEMS Yeast Res. 2008, 8(6):930-938.

10. Xue X, Wu H, Wang K, Cao J, Shen D: Cryptococcosis by Cryptococcus gattii in China. Lancet Infect Dis. 2015, 15(10):1135-1136.

11. Chen YC, Chang SC, Shih CC, Hung CC, Luhbd KT, Pan YS, Hsieh WC: Clinical features and in vitro susceptibilities of two varieties of Cryptococcus neoformans in Taiwan. Diagn Microbiol Infect Dis. 2000, 36(3):175-183. 
12. Torres-Rodriguez JM, Alvarado-Ramirez E, Murciano F, Sellart M: MICs and minimum fungicidal concentrations of posaconazole, voriconazole and fluconazole for Cryptococcus neoformans and Cryptococcus gattii. J Antimicrob Chemother. 2008, 62(1):205-206.

13. Datta K, Bartlett KH, Baer R, Byrnes E, Galanis E, Heitman J, Hoang L, Leslie MJ, MacDougall L, Magill SS et al: Spread of Cryptococcus gattii into Pacific Northwest region of the United States. Emerg Infect Dis. 2009, 15(8):1185-1191.

14. Hagen F, Illnait-Zaragozi MT, Bartlett KH, Swinne D, Geertsen E, Klaassen CH, Boekhout T, Meis JF: In vitro antifungal susceptibilities and amplified fragment length polymorphism genotyping of a worldwide collection of 350 clinical, veterinary, and environmental Cryptococcus gattii isolates. Antimicrob Agents Chemother. 2010, 54(12):5139-5145.

15. Espinel-Ingroff A, Aller Al, Canton E, Castanon-Olivares LR, Chowdhary A, Cordoba S, Cuenca-Estrella M, Fothergill A, Fuller J, Govender N et al: Cryptococcus neoformans-Cryptococcus gattii species complex: an international study of wild-type susceptibility endpoint distributions and epidemiological cutoff values for fluconazole, itraconazole, posaconazole, and voriconazole. Antimicrob Agents Chemother. 2012, 56(11):5898-5906.

16. Espinel-Ingroff A, Chowdhary A, Cuenca-Estrella M, Fothergill A, Fuller J, Hagen F, Govender N, Guarro J, Johnson E, Lass-Florl C et al: Cryptococcus neoformans-Cryptococcus gattii species complex: an international study of wild-type susceptibility endpoint distributions and epidemiological cutoff values for amphotericin B and flucytosine. Antimicrob Agents Chemother. 2012, 56(6):3107-3113.

17. Lockhart SR, Iqbal N, Bolden CB, DeBess EE, Marsden-Haug N, Worhle R, Thakur R, Harris JR: Epidemiologic cutoff values for triazole drugs in Cryptococcus gattii: correlation of molecular type and in vitro susceptibility. Diagn Microbiol Infect Dis. 2012, 73(2):144-148.

18. Lockhart SR, Iqbal N, Harris JR, Grossman NT, DeBess E, Wohrle R, Marsden-Haug N, Vugia DJ: Cryptococcus gattii in the United States: genotypic diversity of human and veterinary isolates. PloS one. 2013, 8(9):e74737.

19. Bielska E, May RC: What makes Cryptococcus gattii a pathogen? FEMS Yeast Res. 2016, 16(1):fov106.

20. Ngamskulrungroj P, Chang Y, Sionov E, Kwon-Chung KJ: The primary target organ of Cryptococcus gattii is different from that of Cryptococcus neoformans in a murine model. mBio. 2012,3(3).

21. Chen SC, Meyer W, Sorrell TC: Cryptococcus gattii infections. Clin Microbiol Rev.2014, 27(4):980-1024.

22. Ngamskulrungroj P, Serena C, Gilgado F, Malik R, Meyer W: Global VGlla isolates are of comparable virulence to the major fatal Cryptococcus gattii Vancouver Island outbreak genotype. Clin Microbiol Infect. 2011, 17(2):251-258.

23. Kwon-Chung KJ, Polacheck I, Bennett JE: Improved diagnostic medium for separation of Cryptococcus neoformans var. neoformans (serotypes A and D) and Cryptococcus neoformans var. gattii (serotypes B and C). J Clin Microbiol. 1982, 15(3):535-537.

24. Meyer W, Aanensen DM, Boekhout T, Cogliati M, Diaz MR, Esposto MC, Fisher M, Gilgado F, Hagen F, Kaocharoen S et al: Consensus multi-locus sequence typing scheme for Cryptococcus neoformans and Cryptococcus gattii. Med Mycol. 2009, 47(6):561-570.

25. Fraser JA, Giles SS, Wenink EC, Geunes-Boyer SG, Wright JR, Diezmann S, Allen A, Stajich JE, Dietrich FS, Perfect JR et al: Same-sex mating and the origin of the Vancouver Island Cryptococcus gattii outbreak. Nature. 2005, 437(7063):1360-1364.

\section{Tables}

Table 1 The geographical region of the isolation, species identification, antifungal susceptibility profile, genotype and sequence type of 8 C. gattii strains

\begin{tabular}{|c|c|c|c|c|c|c|c|c|c|c|c|c|c|c|c|c|c|}
\hline \multirow{2}{*}{$\begin{array}{l}\text { Isolate } \\
\text { No. }\end{array}$} & \multirow{2}{*}{$\begin{array}{l}\text { ID by VITEK } 2 \\
\text { Compact } \\
\text { (Identification } \\
\text { rate) }\end{array}$} & \multirow{2}{*}{$\begin{array}{l}\text { pigmentation } \\
\text { on CGB agar }\end{array}$} & \multirow{2}{*}{$\begin{array}{l}\text { ID by } \\
\text { MALDI-TOF } \\
\text { MS } \\
\text { (score) }\end{array}$} & \multirow{2}{*}{$\begin{array}{l}\text { geographical } \\
\text { region of the } \\
\text { isolation }\end{array}$} & \multirow[t]{2}{*}{ STs } & \multirow[t]{2}{*}{ Genotype } & \multicolumn{2}{|c|}{ 5-FU } & \multicolumn{2}{|l|}{ AMB } & \multicolumn{2}{|c|}{ FCA } & \multicolumn{2}{|l|}{ ITR } & \multicolumn{2}{|c|}{ VRC } & \multirow{2}{*}{$\begin{array}{l}\text { PSZ } \\
\mathrm{b}\end{array}$} \\
\hline & & & & & & & $\mathrm{a}$ & $\mathrm{b}$ & $\mathrm{a}$ & $\mathrm{b}$ & $\mathrm{a}$ & $\mathrm{b}$ & $\mathrm{a}$ & $\mathrm{b}$ & $\mathrm{a}$ & $\mathrm{b}$ & \\
\hline 1 & $\begin{array}{l}\text { C. } \\
\text { neoformans } \\
(93 \%)\end{array}$ & blue & $\begin{array}{l}\text { C. } \\
\text { gattii (2.190) }\end{array}$ & $\begin{array}{l}\text { temperate } \\
\text { regions }\end{array}$ & 20 & VGII & $<4$ & 2 & $<0.5$ & 1 & 8 & 32 & 0.25 & 0.25 & 0.25 & 0.25 & 0.25 \\
\hline 2 & $\begin{array}{l}\text { C. } \\
\text { neoformans } \\
(90 \%)\end{array}$ & blue & $\begin{array}{l}\text { C. } \\
(2.043)\end{array}$ & $\begin{array}{l}\text { tropical } \\
\text { areas }\end{array}$ & 106 & VGI & $<4$ & 0.5 & $<0.5$ & 0.25 & 1 & 4 & $<0.125$ & 0.06 & 0.06 & 0.06 & 0.06 \\
\hline 3 & $\begin{array}{l}\text { C. } \\
\text { neoformans } \\
(96 \%)\end{array}$ & blue & $\begin{array}{l}\text { C. } \\
2.275)\end{array}$ gattii( & $\begin{array}{l}\text { subtropical } \\
\text { area }\end{array}$ & 57 & VGI & $<4$ & 0.5 & $<0.5$ & 0.25 & 1 & 4 & $<0.125$ & 0.12 & 0.06 & 0.12 & 0.12 \\
\hline 4 & $\begin{array}{l}\text { C. } \\
\text { neoformans } \\
(99 \%)\end{array}$ & blue & $\begin{array}{l}\text { C. } \\
(2.092)\end{array}$ gattii & $\begin{array}{l}\text { subtropical } \\
\text { area }\end{array}$ & 197 & VGI & $<4$ & 1 & $<0.5$ & 0.25 & 2 & 4 & $<0.125$ & 0.06 & $<0.125$ & 0.06 & 0.12 \\
\hline 5 & $\begin{array}{l}\text { C. } \\
\text { neoformans } \\
(86 \%)\end{array}$ & blue & $\begin{array}{l}\text { C. } \\
(2.118)\end{array}$ gattii & $\begin{array}{l}\text { temperate } \\
\text { regions }\end{array}$ & 57 & VGI & $<4$ & 0.5 & $<0.5$ & 0.25 & 2 & 4 & $<0.125$ & 0.12 & 0.06 & 0.06 & 0.12 \\
\hline 6 & $\begin{array}{l}\text { C. } \\
\text { neoformans } \\
(91 \%)\end{array}$ & blue & $\begin{array}{l}\text { C. } \\
(2.126)\end{array}$ gattii & $\begin{array}{l}\text { tropical } \\
\text { areas }\end{array}$ & 7 & VGII & $<4$ & 2 & $<0.5$ & 0.5 & 8 & 128 & 0.25 & 0.25 & 0.25 & 0.25 & 0.5 \\
\hline 7 & $\begin{array}{l}\text { C. } \\
\text { neoformans } \\
(98 \%)\end{array}$ & blue & $\begin{array}{l}\text { C. } \\
(2.188)\end{array}$ gattii & $\begin{array}{l}\text { subtropical } \\
\text { area }\end{array}$ & 57 & VGI & $<4$ & 0.5 & $<0.5$ & 0.25 & 1 & 4 & $<0.125$ & 0.06 & 0.06 & 0.06 & 0.12 \\
\hline 8 & $\begin{array}{l}\text { C. } \\
\text { neoformans } \\
(99 \%)\end{array}$ & blue & $\begin{array}{l}\text { C. } \\
(2.194)\end{array}$ gattii & $\begin{array}{l}\text { temperate } \\
\text { regions }\end{array}$ & 161 & VGI & $<4$ & 1 & $<0.5$ & 0.25 & 2 & 4 & $<0.125$ & 0.12 & 0.06 & 0.06 & 0.12 \\
\hline
\end{tabular}

Notes: a and b represented the method of ATB fungus 3 and Yeast one respectively; the abbreviations for antifungal drugs were: 5-FU: 5-Flucytosine; AMB: Amphotericin B; FCA: Fluconazole; ITR: Itraconazole; VRC: Voriconazole; PSZ: Posaconazole.

Table 2 Clinical and laboratory information for patients infected with $C$. gattii 


\begin{tabular}{|c|c|c|c|c|c|c|c|}
\hline & 1 & 2 & 4 & 5 & 6 & 7 & 8 \\
\hline $\begin{array}{l}\text { Location (Province) } \\
\text { isolation period of } C \text {. }\end{array}$ & $\begin{array}{l}\text { Shangdong } \\
2014.11\end{array}$ & $\begin{array}{l}\text { Hainan } \\
2015.12\end{array}$ & $\begin{array}{c}\text { Fujian } \\
2014.04\end{array}$ & $\begin{array}{l}\text { Neimeng } \\
2016.06\end{array}$ & $\begin{array}{l}\text { Yunnan } \\
2016.07\end{array}$ & $\begin{array}{l}\text { Fujian } \\
2015.09\end{array}$ & $\begin{array}{l}\text { Henan } \\
2016.08\end{array}$ \\
\hline Gender & Male & Male & Male & Male & Male & Male & Male \\
\hline Age-ranges(years old) & $20-40$ & $20-40$ & $20-40$ & $41-60$ & $41-60$ & $20-40$ & $20-40$ \\
\hline History(medical/contact) & No & No & No & No & No & No & No \\
\hline Immunity & Normal & Normal & Normal & Normal & Normal & Normal & Normal \\
\hline Fever & + & + & + & - & + & + & + \\
\hline Headache & + & + & + & + & + & + & - \\
\hline Nausea and Vomiting & - & + & + & + & - & - & - \\
\hline Seizure & - & - & + & - & - & - & - \\
\hline Neck stiffness & + & - & + & + & - & - & - \\
\hline Kernig's sign & + & + & + & - & - & - & - \\
\hline Papilloedema & & & + & + & $\mathrm{I}$ & - & - \\
\hline Lung CT & $\begin{array}{l}\text { Irregular nodule with } \\
\text { spicules and lobulation }\end{array}$ & $\begin{array}{l}\text { Left lower } \\
\text { lung mass }\end{array}$ & Normal & $\begin{array}{l}\text { Left lung } \\
\text { mass }\end{array}$ & $\begin{array}{l}\text { Left lower } \\
\text { lung }\end{array}$ & $\begin{array}{l}\text { Multiple } \\
\text { small }\end{array}$ & $\begin{array}{c}\text { Right } \\
\text { upper lung }\end{array}$ \\
\hline Brain MRI & Meningeal lesions & Normal & $\begin{array}{l}\text { Meningeal } \\
\text { enhancement }\end{array}$ & $\begin{array}{l}\text { Left } \\
\text { lacunar }\end{array}$ & NA & Normal & Normal \\
\hline $\begin{array}{l}\text { Organism also found by } \\
\text { lung biopsy }\end{array}$ & Yes & NA & NA & $\begin{array}{l}\text { infarction } \\
\text { NA }\end{array}$ & NA & Yes & Yes \\
\hline Blood culture & No growth & $\begin{array}{l}\text { No } \\
\text { growth }\end{array}$ & No growth & NA & NA & NA & No growth \\
\hline $\begin{array}{l}\text { Cryptococcal antigen } \\
\text { titre in serum } \\
\text { CSF test: }\end{array}$ & $1: 1024$ & NA & NA & NA & NA & NA & $1: 640$ \\
\hline Pressure (mmH2O) & 260 & 330 & 330 & 330 & NA & 200 & normal \\
\hline Glucose $(\mathrm{mmol} / \mathrm{L})$ & 0.5 & 4.11 & 2.49 & 2.3 & NA & 2.22 & normal \\
\hline Protein $(\mathrm{g} / \mathrm{L})$ & 1.57 & 0.71 & 0.35 & 0.73 & NA & 29 & normal \\
\hline Chloride $(\mathrm{mmol} / \mathrm{L})$ & 111 & 144.7 & 117 & 102 & NA & 126.6 & normal \\
\hline White blood & 377 & 80 & 720 & 91 & NA & 368 & normal \\
\hline $\begin{array}{l}\text { cells }\left(\times 10^{6} \text { cells } / L\right) \\
\text { Ink staining }\end{array}$ & nositive & $n$ & 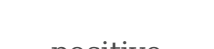 & $x^{2}+2$ & & & \\
\hline Cryptococcal antigen & $\begin{array}{l}\text { positive } \\
1: 1024\end{array}$ & $\begin{array}{l}\text { positive } \\
\text { NA }\end{array}$ & $\begin{array}{l}\text { positive } \\
\text { NA }\end{array}$ & $\begin{array}{l}\text { positive } \\
\text { NA }\end{array}$ & $\begin{array}{l}\text { NA } \\
\text { NA }\end{array}$ & $\begin{array}{l}\text { NA } \\
\text { NA }\end{array}$ & $\begin{array}{l}\text { positive } \\
1: 640\end{array}$ \\
\hline $\begin{array}{c}\text { titre } \\
\text { Organism cultured from }\end{array}$ & CSF & CSF & CSF & $\mathrm{CSF} /$ & sputum & $\mathrm{CSF}$ & sputum \\
\hline Improvement (follow-up) & alive & alive & alive & alive & alive & alive & alive \\
\hline Neurological sequelae & No & No & Yes & No & No & No & No \\
\hline
\end{tabular}

Notes: + and - represented symptoms appeared and not appeared; NA represented data not available.

Table 3 Results of GO enrichment analysis for Cellular Component

\begin{tabular}{ccccc}
\hline GO ID & GO Term & Gene Ratio & Bg Ratio & P value \\
\hline GO:0005794 & Golgi apparatus & 40 & 51 & $3.26 \mathrm{E}-07$ \\
GO:0000139 & Golgi membrane & 26 & 32 & $1.37 \mathrm{E}-05$ \\
\hline GO:0005798 & Golgi-associated vesicle & 12 & 16 & 0.011314374 \\
\hline GO:0031982 & vesicle & 17 & 26 & 0.021147847 \\
\hline GO:0030662 & coated vesicle membrane & 14 & 21 & 0.028770779 \\
\hline GO:0044433 & cytoplasmic vesicle part & 15 & 23 & 0.030922717 \\
GO:0034708 & methyltransferase complex & 4 & 4 & 0.036668632 \\
\hline GO:0030120 & vesicle coat & 12 & 18 & 0.042486706 \\
\hline GO:0098796 & membrane protein complex & 50 & 95 & 0.046997979 \\
GO:0030135 & coated vesicle & 14 & 22 & 0.047857677 \\
\hline GO:0031988 & membrane-bounded vesicle & 15 & 24 & 0.049777137 \\
\hline
\end{tabular}

\section{Figures}




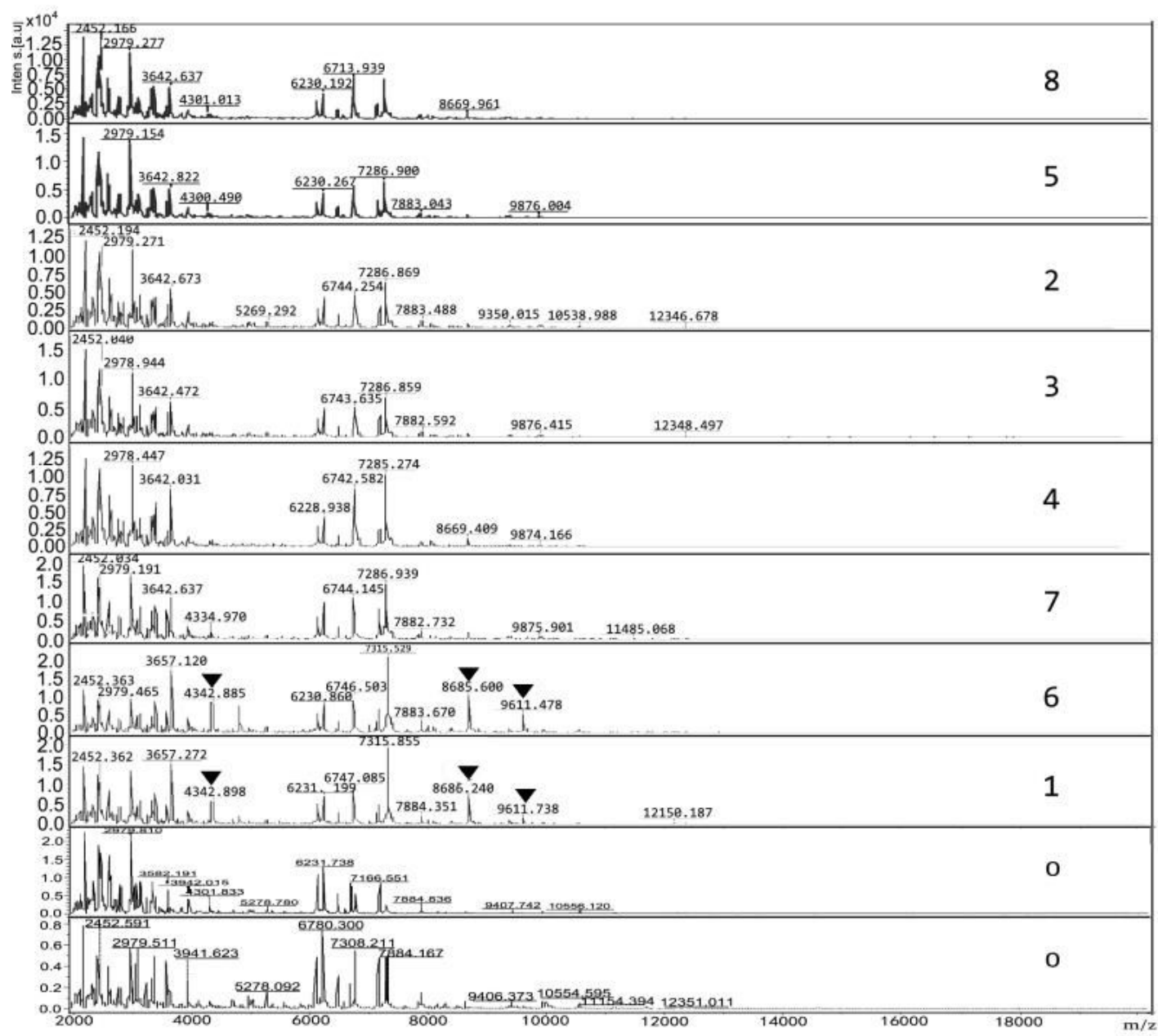

\section{Figure 1}

Mass spectra of 8 strains of C. gattii and 2 strains of C.neoformans by MALDI-TOF MS. Notes: Three specific spectra of C. gattii VGII with molecular weight of about 4342, 8686, 9611 dalton were indicated as arrows; 0 represented C.neoformans. 


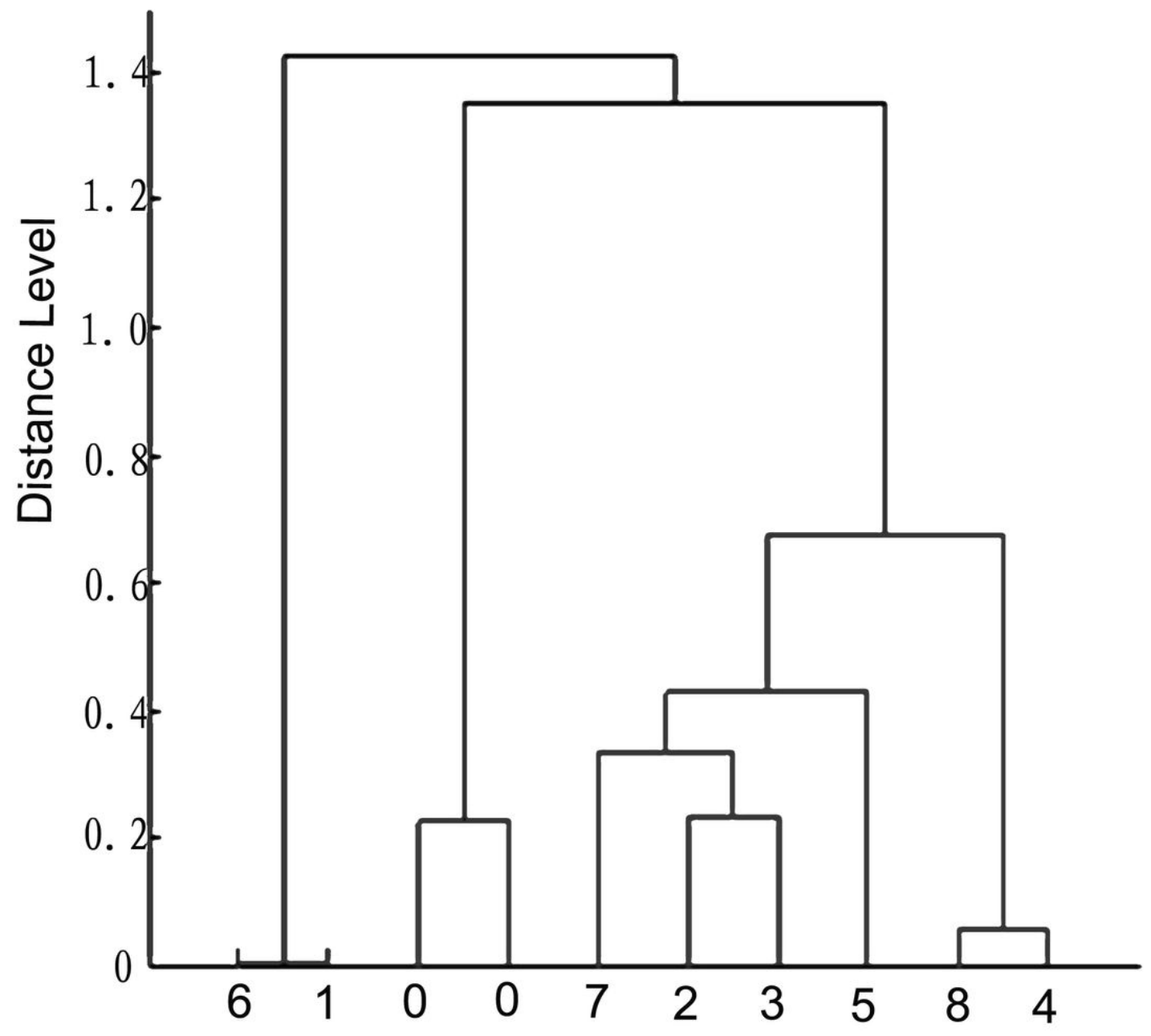

Figure 2

The dendrogram of 8 strains of C. gattii and 2 strains of C.neoformans 
a

R265 1 GCAAATAGTCGRAAGCGLACAATGAACCACTGTTATTTCTAAAAGCATTAACATCTRCC 60

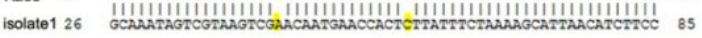
R265 61 ATCTTGCTrCTCCIGCTATAGTGGTATACTGTAAGTGCATCAGCTGGCAGAGTAGCTAAG 120

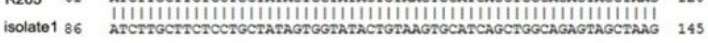

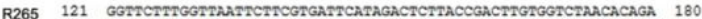

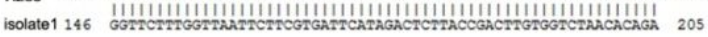

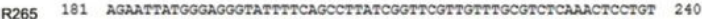

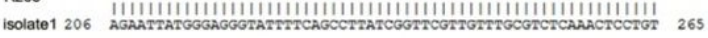
R265 241 TCGCACAACTGATAATGCATCCACTTCCATAGCTTGTATCATCATCTACATCATGGGCCF 300 isolate 1266 TCGCACAACTGATARTGCATCCACTTCCATAGCTTITATCATCATCTACATCATGGOCC 325

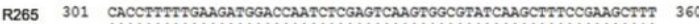

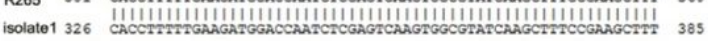

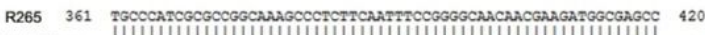
isolate1 386 TGCCCATCGCGCCGGCAMagct R265 421 TGAGAGGCAGCTCACCGAGGAGGACT GGCCGAMGAGCAMGCCATGMAGAGGAGGCTCG 480 isolate 1446 TI111111111111111111111111111111111111111111111111 50

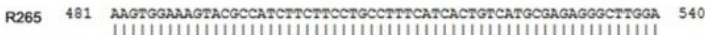
isolate1 506 AIIIIIIIIIIIIIIIIIIIIIIIIIIIIIIIIIIIIIIIIIIIIIIIIIIIII 540 R265 541 GGCTA 545

isolate1 566 GGCTA 570

C

R265 1 GGRGCTARGCGAGMACAATARATGAGGACTGGRATGRGGAGGCACCAGGCTRCTCAMTGG 60

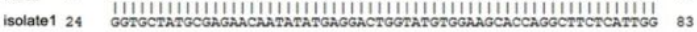

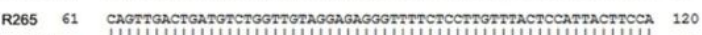

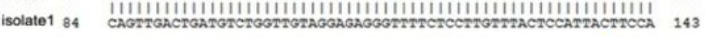

R265 121 GAMGCTCTITCGAMGAAGTANCCACATTCCACCAACAMATTTRGCGOGNGAGRCGGTAMA 180

isolate 144 111111111111111111111111111111111111111111111111111 203

R265 181 TCRCACGTGTAGATGITATTTGGCTGACTAATGATATGACAGGTIAAGGATAAGGATTAC 240

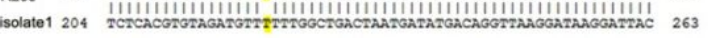

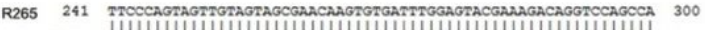

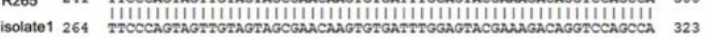

R265 301 CARGGTGAGCTRCTRCARTITTAATCACGTACATCAGCTRAARGRCATGRCAGAGGGGCG 360

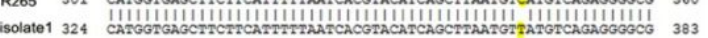

R265 361 TGACTRGGCTAAMAGGTITAATGCCCAATGTAMTGAAACATCCGCCAAGCAACGAGTAMA 420

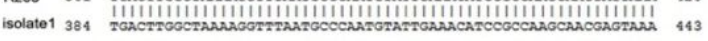

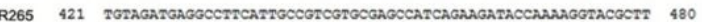

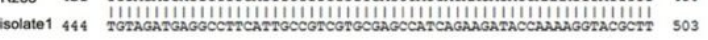

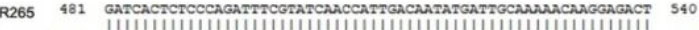

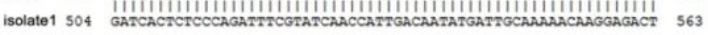

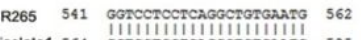

$\mathrm{b}$

R272 1 GCAAATAGTCGTAAGTCGTACAATGAACCACTGTTATTTCTAAAAGCATTAACATCTTCC 60

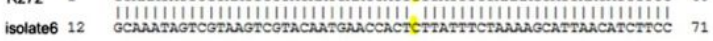
R272 61 ATCTTGCTICTCCTGCTATAGTGOTATACTGTAAGTGCATCAGCTGGCAGAGTAGCTAAG 120 isolate6 72 ATCTIGCTICTCCTGCTATAGTGOTATACTOLAAGTGCARCAGCTGGCAGAGTAGCTAAG 131 R272 121 GGT2CTTTGGTPAATTCTTCGTGATTCATAGACTCTTACCGACTRGTGOTCTAACACAGA 180

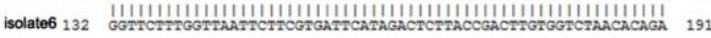

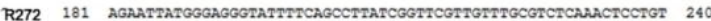

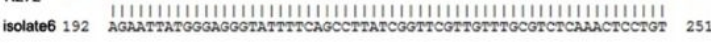
R272 241 TCGCACAACTGATAATGCATCCACTTCCATAGCTTGTATCATCATCTACATCATGGGCCT 300

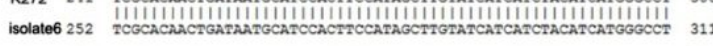
R272 301 CACCTIMTTGAMGATGGACCMATCRCGAGRCAMGTGCGIATCAMGCTITCCGAAGCTIT 360

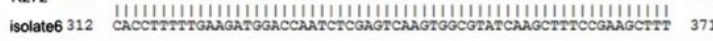

R272 361 TGCOCANCGCGCCGGCAMAGCCCNCTTCAATTTCCGGGGCAACAACGAAGGTGGCGAGCC 420

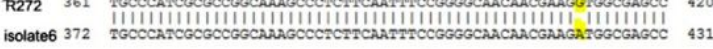
R272 421 TGAGAGGCAGCTCACGGAGGAGGACTCGCCGAMGAGCAMGCCATGAAGAAGAAGGTCG 480

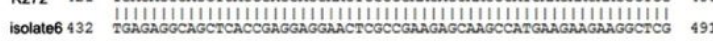
R272 481 AAGRGGARAGTACGCCATCRTCTRCCTGCCTTTCARCACRGTCATGCGAGAGGGCTRGGA 540

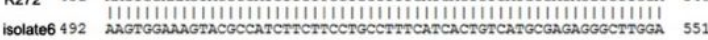
R272 541 GGCTA 545

isolate6 552 GGCTA 556

d

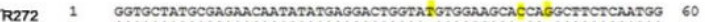

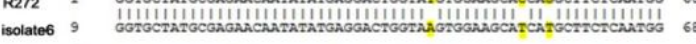

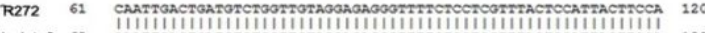
isolate6 69 CAATTG: R272 121 GAAGCTCRTтCGAAGRAORATCCACATTCCACCAACAMATITIGCOGORGAGRCGGTARA 180

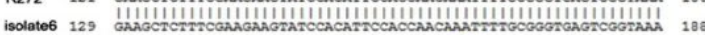

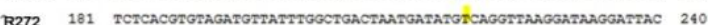

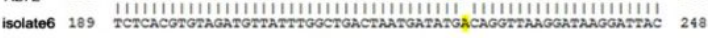

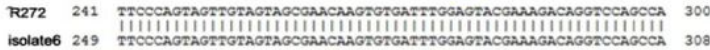

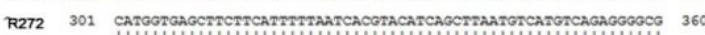

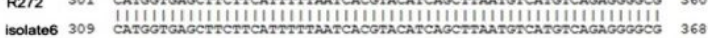

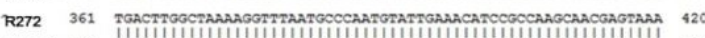

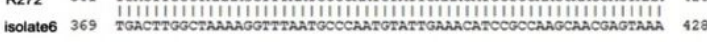
R272 421 TGTAGATGAGGCCTTCATROCCOTCGTGCGAGCCATCAGAMGATACCAARAGOTACGCTT 480

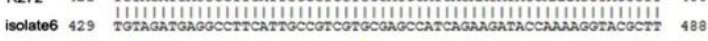

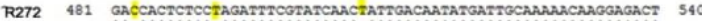

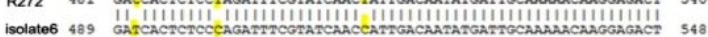
R272 541 gGrectecteaggcrorgana 562

isolate6 549 Gorecrecreagocrorgatili 570

\section{Figure 3}

Gene mutations of 2 VGII strains (isolate number 1 and 6) in unlinked gene loci FTR1 and RAS1 compared with reference strains R265 and R272 


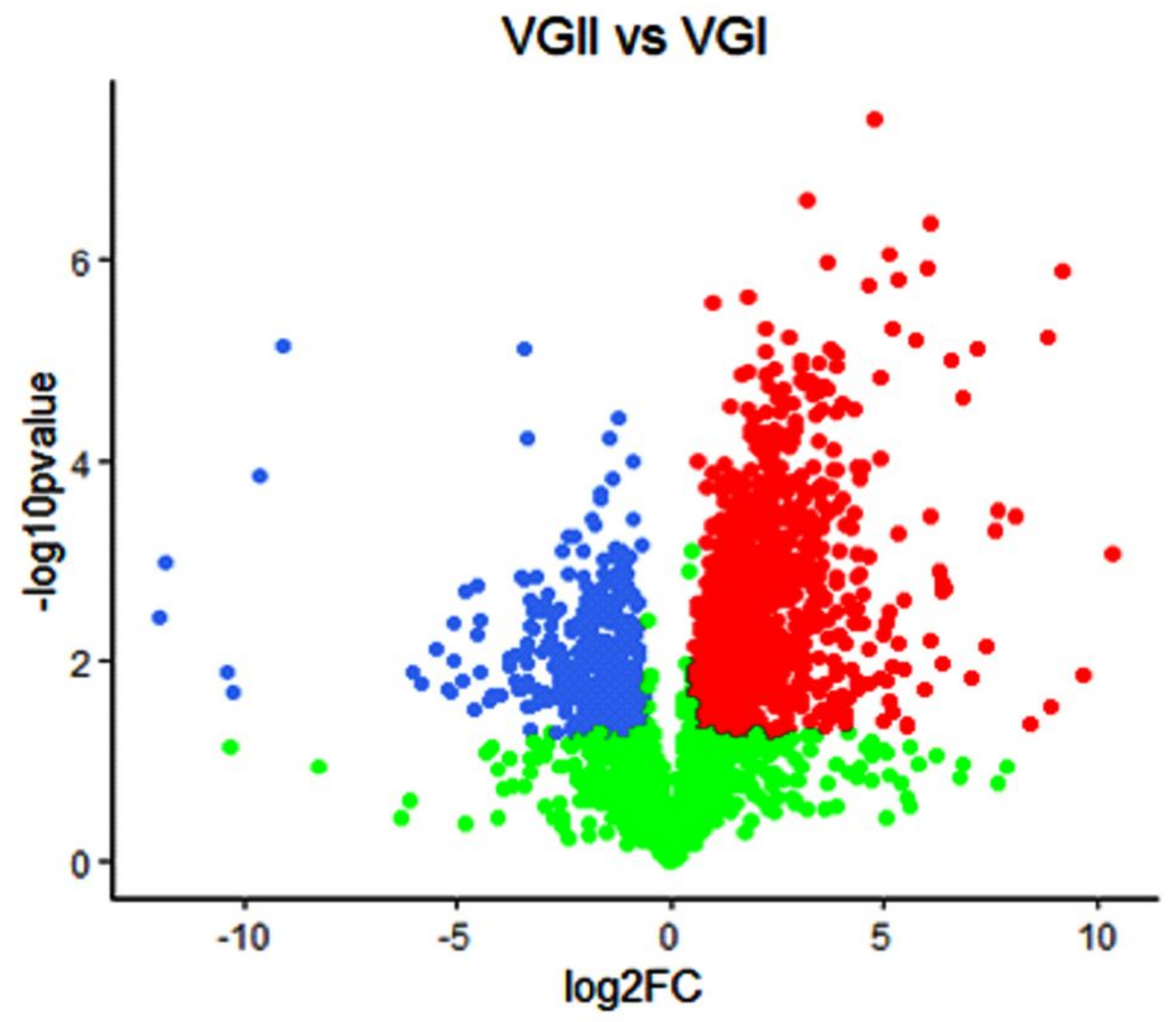

Figure 4

Volcanic map of identified proteins Notes: The red and blue dot represented the profile for 329 and 180 highly expressed proteins of C.gattii VGI and VGII (p $<0.05)$; the green dot represented the proteins without significant difference. 


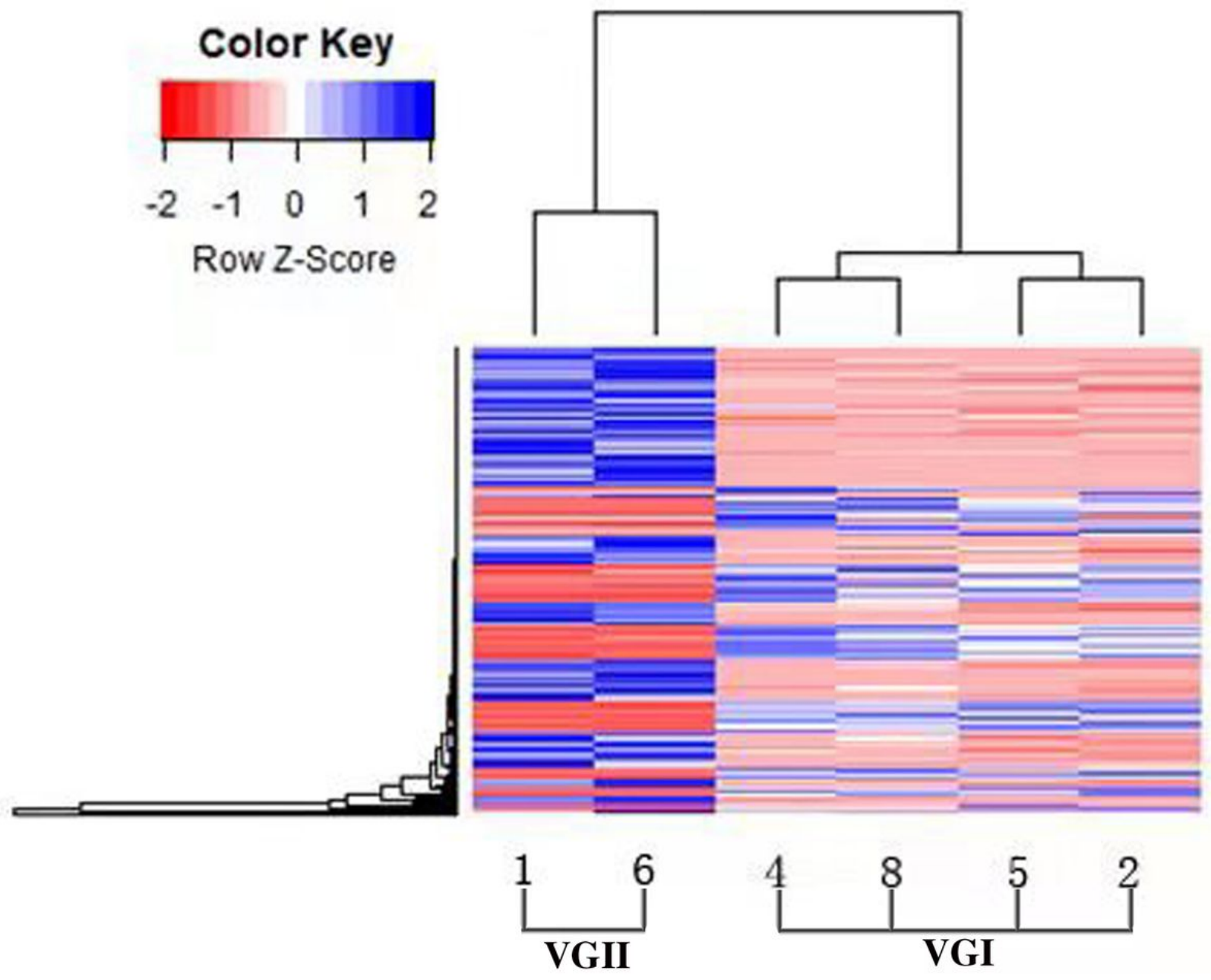

Figure 5

Clustering of differential expression proteins Notes: Blue and red represented high and low expression proteins respectively 


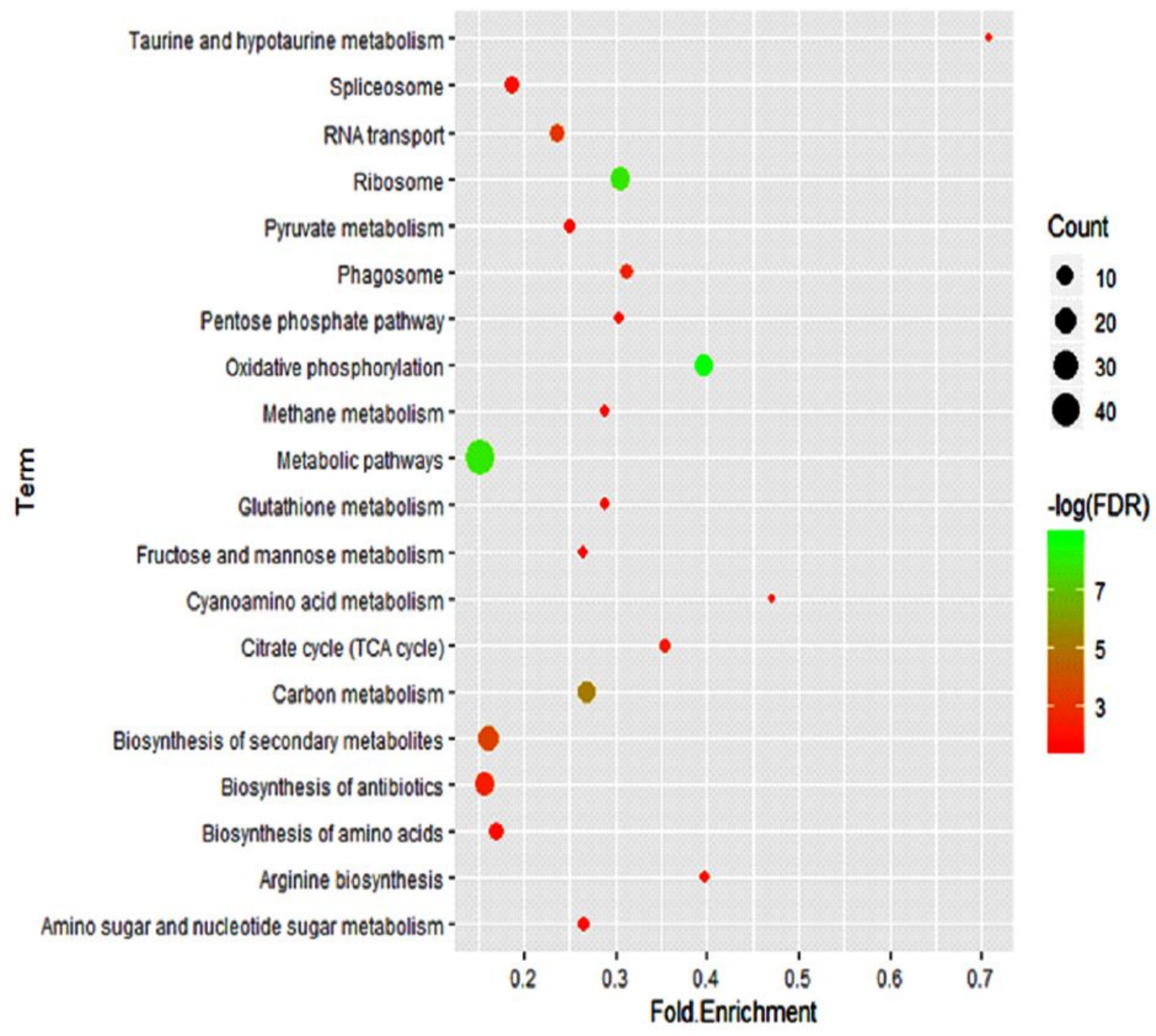

Figure 6

Enrichment Analysis of differential proteins by KEGG metabolic pathway Notes: The circle was used to represent the enrichment of each KEGG term, the diameter of the circle represented the number of differentially expressed genes commented to each KEGG term species, the color of the circle represented the significance of the corresponding KEGG term ( $p$ value corrected by FDR). Bottom transverse coordinate represented "Rich factor", the larger the value, the higher the proportion of the number of differentially expressed genes to the total number of corresponding KEGG term gene.

\section{Supplementary Files}

This is a list of supplementary files associated with this preprint. Click to download.

- SupplementaryTables.docx 